
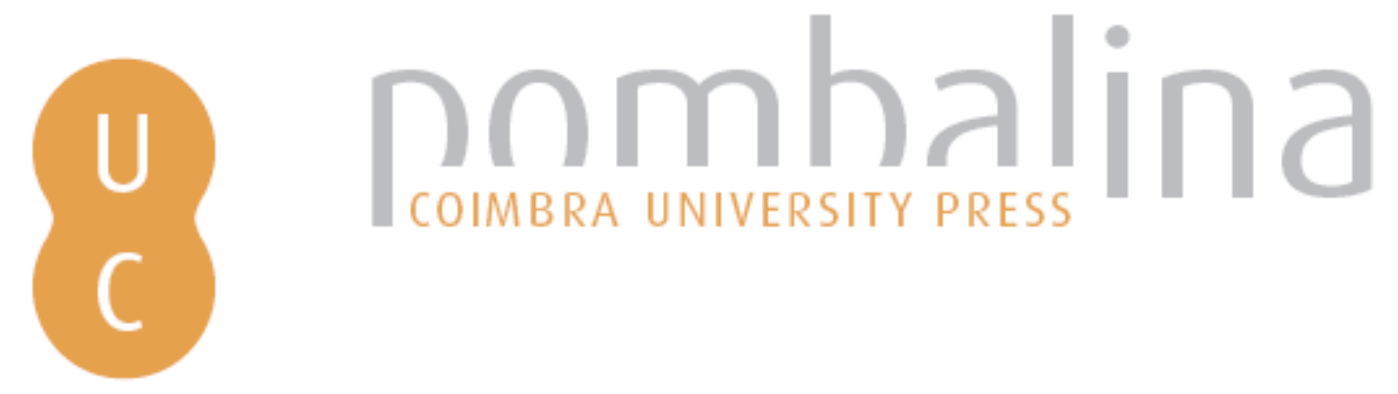

\title{
Aplicação de sistemas de informação geográfica para a análise da morfologia urbana no entorno de terminais de ônibus urbanos
}

\author{
Autor(es): $\quad$ Yamada, Melissa Midori; Sluter, Claudia Robbi; Lima, Cristina de Araújo \\ Publicado por: Imprensa da Universidade de Coimbra \\ URL \\ persistente: URI:http://hdl.handle.net/10316.2/37072 \\ DOI: $\quad$ DOI:http://dx.doi.org/10.14195/978-989-26-0983-6_19 \\ Accessed : $\quad$ 26-Apr-2023 15:15:34
}

A navegação consulta e descarregamento dos títulos inseridos nas Bibliotecas Digitais UC Digitalis, UC Pombalina e UC Impactum, pressupõem a aceitação plena e sem reservas dos Termos e Condições de Uso destas Bibliotecas Digitais, disponíveis em https://digitalis.uc.pt/pt-pt/termos.

Conforme exposto nos referidos Termos e Condições de Uso, o descarregamento de títulos de acesso restrito requer uma licença válida de autorização devendo o utilizador aceder ao(s) documento(s) a partir de um endereço de IP da instituição detentora da supramencionada licença.

Ao utilizador é apenas permitido o descarregamento para uso pessoal, pelo que o emprego do(s) título(s) descarregado(s) para outro fim, designadamente comercial, carece de autorização do respetivo autor ou editor da obra.

Na medida em que todas as obras da UC Digitalis se encontram protegidas pelo Código do Direito de Autor e Direitos Conexos e demais legislação aplicável, toda a cópia, parcial ou total, deste documento, nos casos em que é legalmente admitida, deverá conter ou fazer-se acompanhar por este aviso.

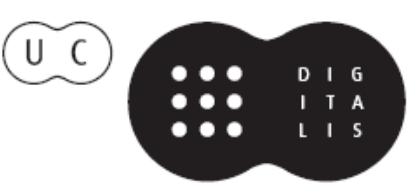




\section{$\forall$ \\ TAS DAS I JORNADAS LUSÓFONAS DE CIÊNCIAS E TECNOLOGIAS DE INFORMAÇÃO GEOGRÁFICA}

Editores

José Gomes dos Santos

Cidália Fonte

Rui Ferreira de Figueiredo

Alberto Cardoso

Gil Gonçalves

José Paulo Almeida

Sara Baptista 


\section{A RTI G O 19}

\section{APLICAÇÃo DE SISTEMAS DE INFORMAÇÃo GEOGRÁfiCA PARA A Análise da Morfologia URBANA No ENTORNo DE TERMINAIS DE ÔNIBUS URBANOS}

YAMADA, Melissa Midori ${ }^{1}$, SLUTER Claudia Robbi ${ }^{2}$ E LIMA, Cristina de Araújo ${ }^{3}$

\footnotetext{
${ }^{1}$ Universidade Federal do Paraná; Setor de Ciências da Terra - Departamento de Geomática, Curitiba - PR Rua Cel. Francisco Heráclito dos Santos, 210 - Jardim das Américas - Curitiba - Paraná - Brasil; Tel.: +55 41 96852583; e-mail: miel.my@gmail.com

${ }^{2}$ Universidade Federal do Paraná; Setor de Ciências da Terra - Departamento de Geomática, Curitiba - PR Rua Cel. Francisco Heráclito dos Santos, 210 - Jardim das Américas - Curitiba - Paraná - Brasil; Tel.: +55 4199319647 ;E-mail: robbi@ufpr.br

3 Universidade Federal do Paraná; Setor de Tecnologia - Departamento de Arquitetura e Urbanismo; Rua Cel. Francisco Heráclito dos Santos, 210 - Jardim das Américas - Curitiba - Paraná - Brasil; Tel. +55 (41) 3361-3490 / 3361-3085/ 9199 4523; E-mail: cristinadearaujolima@gmail.com
}

\section{RESUMO}

Com este trabalho propõe-se uma metodologia baseada no uso de um SIG para o entendimento da morfologia urbana no entorno dos terminais de ônibus urbano, no município de Curitiba e Região Metropolitana, Estado do Paraná, Brasil. O objetivo em se conhecer a morfologia urbana é compreender a dinâmica e a forma da ocupação dessas áreas. A grande quantidade de informação disponível para as análises espaciais sugerem o uso de um Sistema de Informação Geográfica (SIG) por ser uma tecnologia capaz de aliar dados espaciais com os socioeconômicos. Nesse estudo de caso, fizemos um recorte das áreas amostrais no entorno dos terminais de ônibus urbano que fazem parte do sistema de transporte publico de Curitiba. A metodologia foi definida com o objetivo de entender a morfologia urbana de acordo com sua densidade, uso do solo, tipologia das quadras, e paisagem. E as 
análises demonstram que a ocupação do solo se configura de maneiras diversas de acordo com a região em que se encontra, apesar da dinâmica dos terminais em si ser a mesma.

\title{
PALAVRAS-CHAVE
}

SIG, Morfologia urbana, Ocupação urbana, Uso do solo.

\section{USING GIS TO ANALYZE THE URBAN MORPHOLOGY NEARBY THE URBAN BUS STATIONS}

\begin{abstract}
Urban morphology is one of the issues about urban planning that GIS spatial analysis can assist the understanding of it. The proposition of methods to perform spatial analysis as the basis for understanding the urban morphology nearby the urban bus stations of public transportation system is a requirement to know how is the urban dynamics around these areas. The amount of information available to characterize such areas is huge, and GIS is a technology able to link the physical space with socio-economic forces that shape it. In the case study we describe the urban morphology nearby the urban bus stations of the public transportation system in the city of Curitiba (State of Parana, Brazil). We chose three bus stations as our case study and we analyzed those bus station areas according to a methodology defined by urban planners. According to this methodology, urban morphology can be defined in accordance with the density, the land use, the typology of the street blocks, as well as the landscape features. Based on the result analysis we conclude the urban morphology of the areas located in the central part of the city if different from suburban area.
\end{abstract}

\section{KEYWORDS}

GIS, Urban morphology, Urban occupancy, Land use.

\section{INTRODUÇÃo}

A análise morfológica, considerando que a cidade pode ser entendida pelas suas formas físicas, foi adotada pelos membros da International Seminar on Urban Form (ISUF) a partir de três bases teóricas: a forma, a escala e o tempo. Com o passar do tempo foram incorporadas às análises morfológicas, questões socioeconômicas e culturais (KROPF, 2005). Conforme Moudon (1997), a cidade é a acumulação e a integração de diversos atores, individuais e grupos, governados por suas tradições culturais e conformados pelas forças sociais e econômicas ao longo do 
tempo. A interdisciplinaridade e a acessibilidade à grande quantidade de informação para análises espaciais, aliadas ao avanço das tecnologias, faz com que o desenvolvimento de um Sistema de Informação Geográfica (SIG) seja uma solução pertinente às análises morfológicas, por ser a tecnologia que possibilita a conciliação dos dados físicos com os dados socioeconômicos.

Esse trabalho foi desenvolvido no município de Curitiba, capital do Estado do Paraná, Brasil, a partir das diretrizes de urbanismo do Plano Diretor de 1966, quando a estrutura urbana foi definida por eixos estruturais viários, nordeste-sudoeste e leste-oeste e posteriormente outro eixo ao sul, denominado Boqueirão (SOUZA, 2001). Consolidados esses eixos, foram construídos, ao longo do tempo, as linhas de ônibus denominadas "interbairros" e os "alimentadores" que fazem a ligação entre os eixos principais e abrangem os municípios da Região Metropolitana de Curitiba (RMC) pela Rede Integrada de Transporte - RIT. A Figura 1 apresenta um esquema geral dos eixos estruturais, as linhas interbairros e alimentadoras, como também os terminais de transporte.

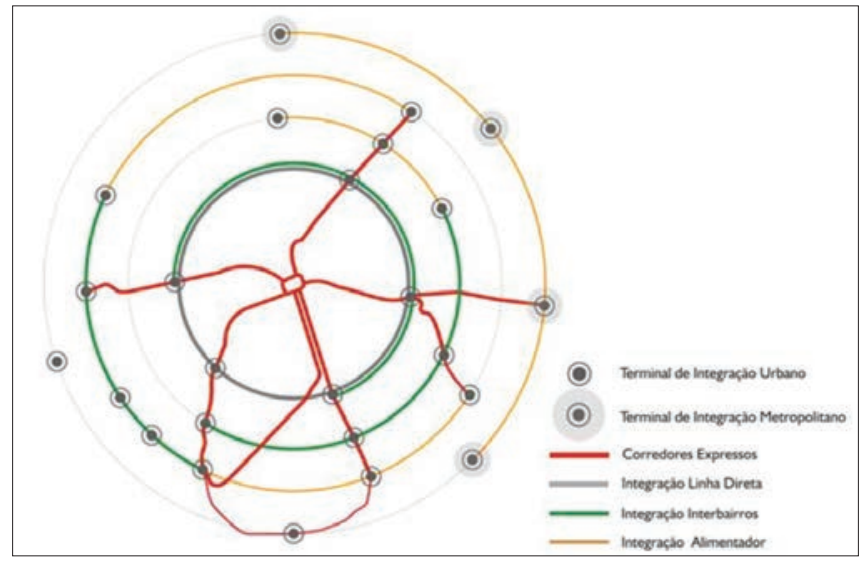

Figura 1 - Esquema da Rede Integrada de Transporte de Curitiba Fonte: URBS, 2014

Nesse contexto, o estudo da morfologia urbana no entorno dos terminais de transporte urbano, é importante para o entendimento das formas de ocupação ao longo dos eixos estruturais da cidade, onde circula o modal de transporte mais importante, que é o sistema público de ônibus, e que 
se configuram como as principais ligações da população dos municípios pertencentes ao aglomerado urbano denominado NUC (Núcleo Urbano Central de Curitiba). Nesta pesquisa entende-se morfologia urbana como o estudo das características formais do espaço urbano relacionando a arquitetura com a estrutura urbanística, condições físicas, socioeconômicas, políticas e culturais (LAMAS, 2000), sendo seu estudo ferramenta que subsidia o planejamento urbano e regional.

\section{APRESENTAÇÃo DO TEMA}

Este trabalho apresenta a aplicação de um SIG nas análises espaciais para o entendimento da morfologia urbana no que concerne os terminais de transportes públicos urbanos de Curitiba e municípios pertencentes ao Núcleo Urbano Central (NUC) da Região Metropolitana de Curitiba (RMC) ${ }^{1}$. A Rede Integrada de Transportes (RIT) é composta de 22 (vinte e dois) terminais públicos urbanos, sendo que para esse estudo foram selecionados 3 (três) destes terminais, um localizado na região central e os outros dois em bairros residenciais ao norte e ao sul do município de Curitiba (Figura 2).

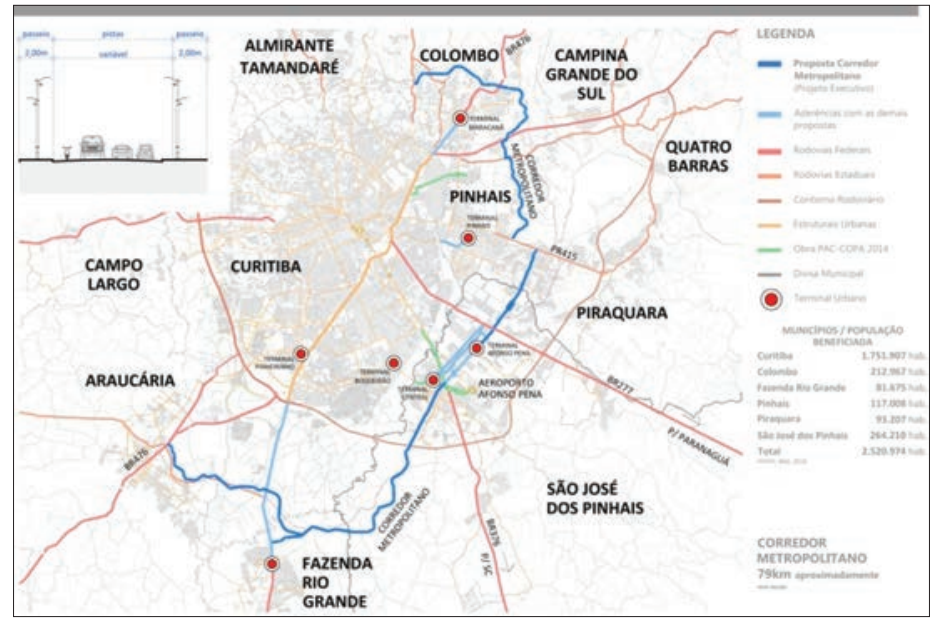

Figura 2 - Localização dos Terminais Fonte: adaptado de COMEC, 2005

1 De forma colaborativa com os objetivos do Projeto de Pesquisa "Cidade, mobilidade, energia e governança”, registro 2012001660 - UFPR, em desenvolvimento. 


\section{METODOLOGIA}

Os procedimentos metodológicos adotados foram divididos em quatro etapas: (i) a delimitação das áreas geográficas, (ii) o entendimento e classificação da densidade da ocupação urbana, (iii) a verificação e classificação dos usos existentes e (iv) identificação do zoneamento existente conforme a legislação de uso do solo - Lei $n^{\circ} 9.800$ de 3 de janeiro de 2000.

Moudon (1997) apresenta em uma de suas bases teóricas, três elementos físicos fundamentais a serem utilizados para a análise da forma urbana: edifícios e a relação com os espaços abertos, lotes e ruas. Assim, para esse trabalho, utilizamos as seguintes informações geográficas: arruamentos, quadras, lotes, edificações, para o entendimento da forma urbana, e setores censitários e zoneamento do uso do solo para os aspectos socioeconômicos.

Para a delimitação geográfica de cada área amostral, geramos um buffer de 250 metros a partir do polígono do terminal. Com essa medida englobamos aproximadamente duas quadras e de acordo com os indicadores de acessibilidade locacional dos serviços de transporte público está classificada como uma qualidade de serviço de boa para ótima (ALTER, 1976). Além de ser a distância adotada para a localização dos pontos de ônibus em Curitiba. Com os dados atingidos por esse buffer foi criado um banco de dados específico do terminal a ser estudado. Para o entendimento e classificação da densidade da ocupação urbana realizamos quatro tipos de análises espaciais: densidade espacial, taxa de aproveitamento, densidade populacional e tipologia de quadras. A densidade espacial foi analisada pela relação do espaço construído com o espaço livre, através da visualização de figura-fundo, criando um contraste entre as edificações e os espaços livres das quadras (LEVY, 1999). Para a taxa de aproveitamento foram tabulados e classificados os dados do número de pavimentos das edificações, adquiridos a partir de levantamento em campo e então, tabulados junto aos respectivos vetores. Para a densidade populacional, fizemos a estimativa da população por quadra proporcionalmente à área que esta atinge do setor censitário, de modo a gerar os dados necessários para o entendimento da densidade populacional. E no que concerne a tipologia das quadras, fizemos uma análise visual 
comparando a figura-fundo gerada para a análise da densidade espacial com as bases do modelo proposto por Rodrigues (1986).

O modelo de Rodrigues (1986) sugere quatro tipologias: F-F (fechado-fechado), A-A (aberto-aberto), A-F (aberto-fechado) e F-A (fechado-aberto). O modelo F-F é aquele em que a quadra encontra-se com as testadas das edificações alinhadas e encostadas umas nas outras e com o miolo de quadra ocupado. No modelo A-A as edificações são construídas utilizando o recuo do alinhamento predial do lote e existe algum espaço no miolo da quadra. O modelo A-F é aquele em que as edificações estão no recuo, mas o miolo de quadra está todo ocupado, e no modelo F-A as edificações encontram-se no alinhamento predial, encostadas umas nas outras, sem o recuo lateral, mas possuem espaço livre no interior da quadra. A verificação e classificação dos usos existentes nas áreas amostrais foram possíveis a partir do levantamento de dados em campo, classificando as edificações de acordo com o uso residencial, comercial, industrial, institucional, serviço e somatório de usos. Essa classificação dos usos forneceu dados da porcentagem de usos por quadra e por amostra e a relação entre usos dentro da amostra. A legislação vigente forneceu dados sobre o zoneamento e os usos permissíveis a cada um dos três terminais, o tamanho do lote padrão e número máximo de pavimentos, que foram tabulados e comparados com os dados levantados em campo.

\section{APRESENTAÇÃo DOS DADOS}

Um dos aspectos estruturantes da análise do uso e ocupação do solo envolve o transporte público urbano e o sistema viário que o incorpora. Para tal, foram escolhidas três áreas amostrais: terminal Boqueirão, terminal Cabral e terminal Praça Rui Barbosa. Este SIG foi desenvolvido de forma a propiciar as informações para o entendimento da morfologia urbana dessas três áreas amostrais. A geovisualização permite a exploração dos dados espaciais em diversos formatos: estatísticas, mapas e representações em 3D. O uso do SIG auxilia na compilação e análise dos dados das etapas metodológicas. 


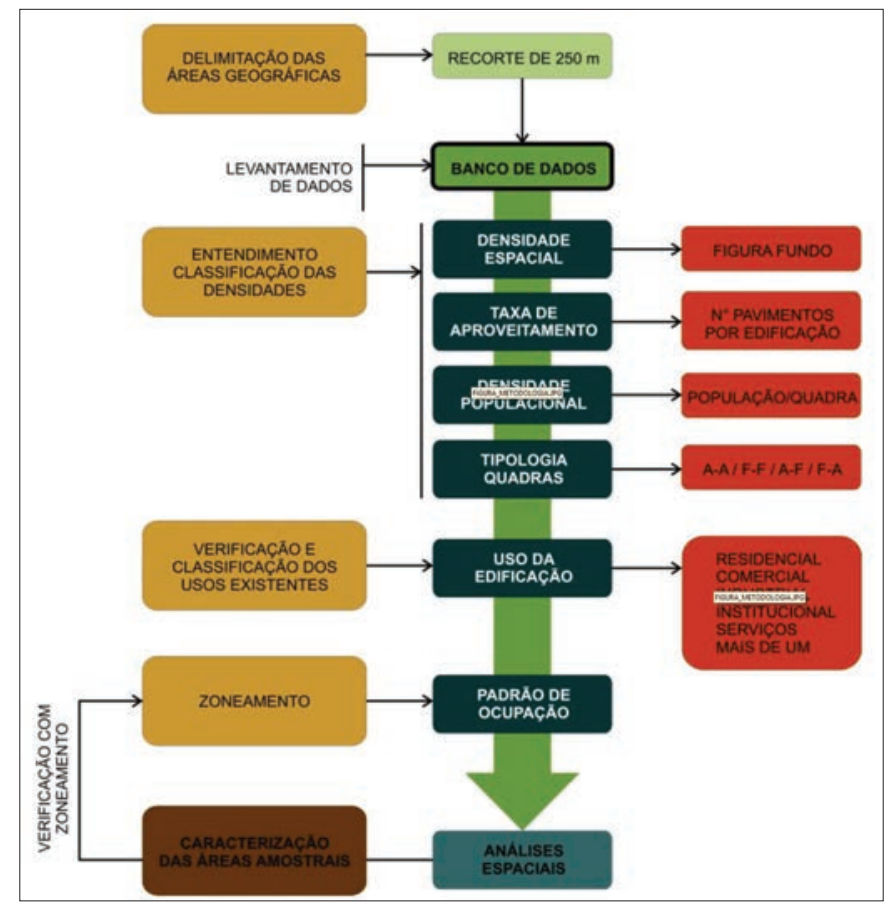

Figura 3 - Esquema da Metodologia

Primeiramente, em relação à densidade espacial, o terminal Praça Rui Barbosa possui suas edificações ocupando quase 100\% da área do lote, restando pouca área livre. No terminal Cabral as edificações ocupam uma média de $45 \%$ da quadra, e no terminal Boqueirão uma média de $70 \%$. Com isso vemos que o terminal Boqueirão mesmo não possuindo a maior densidade ocupacional, tem a maior densidade de edificações por quadra (Tabela 1 e Figura 4).

Tabela 1 - Número edificações por quadra por terminal

\begin{tabular}{|c|c|c|c|}
\hline & Número de quadras & Número de edificações & Edificações por quadra \\
\hline $\begin{array}{c}\text { Terminal do } \\
\text { Boqueirão }\end{array}$ & 18 & 865 & 48,06 \\
\hline $\begin{array}{c}\text { Terminal do } \\
\text { Cabral }\end{array}$ & 24 & 484 & 20,17 \\
\hline Rui Barbosa & 25 & 626 & 25,04 \\
\hline
\end{tabular}




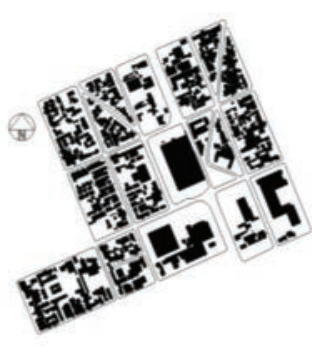

Terminal Boqueirão

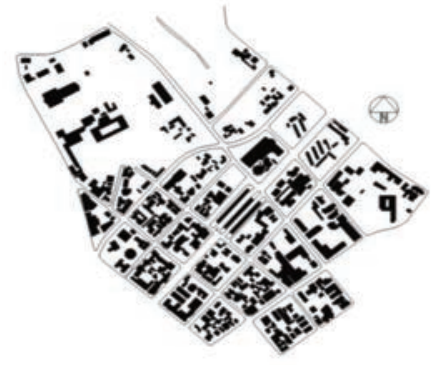

Terminal Cabral

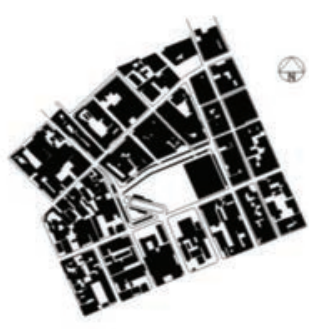

Terminal Rui Barbosa

Figura 4 - Figura-fundo da ocupação nos terminais

Com relação à taxa de aproveitamento, vimos que todos os terminais possuem mais da metade das edificações na classe de 1-2 pavimentos, variando de 50,80\% a 94,68\%. Excluindo essa classe, destacam-se no terminal Boqueirão as edificações de 3-4 pavimentos. No terminal Praça Rui Barbosa constata-se a homogeneidade entre o restante das edificações, ou seja uma média de 3 a 4 pavimentos, com algumas ocorrências de edifícios residenciais com mais de 10 pavimentos (Tabela 2). E o no terminal Cabral a quantidade de edifícios de 7-15 e com mais de 15 pavimentos (Figura 5).

Tabela 2 - Número de pavimentos das edificações por terminal

\begin{tabular}{|c|c|c|c|c|}
\hline \multirow{2}{*}{ Terminal } & \multicolumn{4}{|c|}{ Número de pavimentos (edificações) } \\
\cline { 2 - 5 } & $\mathbf{0 1 - 0 2}$ & $\mathbf{0 3 - 0 6}$ & $\mathbf{0 7 - 1 5}$ & $>\mathbf{1 5}$ \\
\hline Rui Barbosa & 318 & 191 & 66 & 51 \\
\hline Cabral & 402 & 20 & 31 & 31 \\
\hline Boqueirão & 819 & 45 & 0 & 1 \\
\hline
\end{tabular}

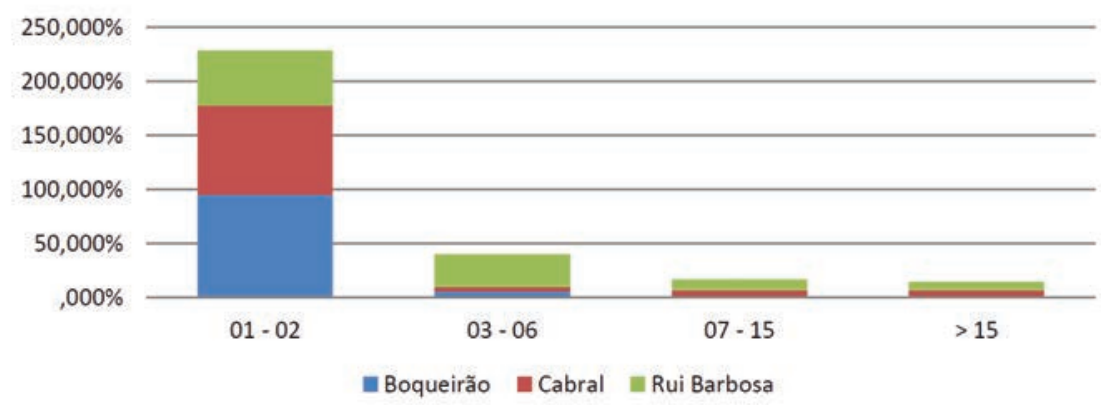

Figura 5 - Percentual do número de pavimentos das edificações por terminal 
A densidade populacional dos terminais mostrou uma população similar entre o terminal Praça Rui Barbosa e terminal Cabral, enquanto no terminal Boqueirão o número de habitantes se resume a 2/3 dos demais (Tabela 3). Quanto à tipologia de quadra, o terminal Praça Rui Barbosa configura um tipo fechado-fechado (F-F), onde as edificações ocupam desde o alinhamento predial até o miolo da quadra, conformando uma quadra inteiramente ocupada, o terminal Cabral aberto-aberto (A-A) onde as edificações estão dispersas, construídas no recuo e ainda existe área livre permeando o interior da quadra e o terminal Boqueirão com a maioria das quadras aberto-aberto (A-A), uma quadra (A-F), onde encontra-se uma edificação recuada que ocupa o interior da quadra e duas que estão praticamente fechado-fechado (F-F) (Figura 4).

Tabela 3 - Número de domicílios, habitantes e média de habitantes por domicílio por terminal

\begin{tabular}{|c|c|c|c|}
\hline & Domicílios & População & Média de morador por domicílio \\
\hline Terminal Boqueirão & 3.554 & 11.030 & 3,10 \\
\hline Terminal Cabral & 5.066 & 12.952 & 2,56 \\
\hline Terminal Rui Barbosa & 3.933 & 8.271 & 2,10 \\
\hline
\end{tabular}

Em relação aos usos predominantes, as áreas amostrais ficaram caracterizadas da seguinte forma: no terminal Cabral o uso residencial, com algum uso comercial, de serviço e institucional; no terminal Praça Rui Barbosa, a predominância da classe "mais de um uso" com algum uso residencial, comercial, de serviço e institucional, e no terminal Boqueirão o uso predominantemente residencial, mas com diversos outros usos, variando entre comercial, de serviço, institucional e industrial (Figura 6 e Figura 7). E por fim, o zoneamento existente nas áreas amostrais que demonstra como a ocupação seguiu as normativas legais sobre o uso do solo. O zoneamento de uso do solo de Curitiba organiza o município em 1 (uma) zona central, 9 (nove) residenciais, 1 (uma) de uso misto, 1 (uma) industrial, 3 (três) de serviços, 3 (três) de transição, 3 (três) especiais, 1 (uma) de contenção e 22 (vinte e dois) setores especiais. A zona de contenção define áreas de preservação permanente, os setores 
especiais e zonas de transição delimitam zonas localizadas ao longo dos eixos estruturais, as zonas especiais incorporam áreas de uso especial (e.g. zona militar), as zonas residenciais são destinadas ao uso habitacional, a zona central e zona de uso misto permitem um uso variado, mas com parâmetros de ocupação diferentes. O terminal Praça Rui Barbosa está na Zona Central, o terminal Cabral possui uma Zona Residencial 4 e o Setor Estrutural, e o terminal Boqueirão está na Zona Residencial 3 e Setores Especiais da Marechal Floriano Peixoto e da Wenceslau Bras (Figura 8). O tamanho do lote mínimo permitido em cada uma das áreas residenciais é diferente, sendo no terminal Cabral lotes de $450 \mathrm{~m}^{2}$, no terminal Boqueirão de $360 \mathrm{~m}^{2}$ e Rui Barbosa de $330 \mathrm{~m}^{2}$, assim como a altura máxima permitida no terminal Boqueirão é de 3 pavimentos, no terminal Cabral é de 6 pavimentos e no terminal Praça Rui Barbosa é livre. Quanto aos setores especiais, a configuração no terminal Cabral e no terminal Boqueirão são as mesmas, de lote mínimo de $450 \mathrm{~m}^{2} \mathrm{com}$ altura livre, mas tendo que considerar um recuo maior respeitando a determinação de um recuo, no mínimo, seis vezes menor que a altura da edificação.

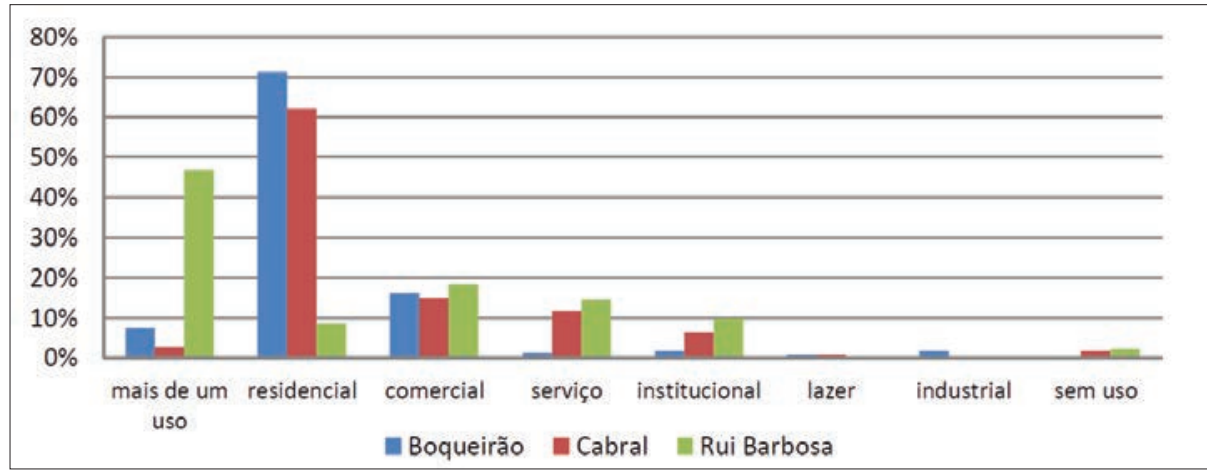

Figura 6 - Usos das edificações por terminal 


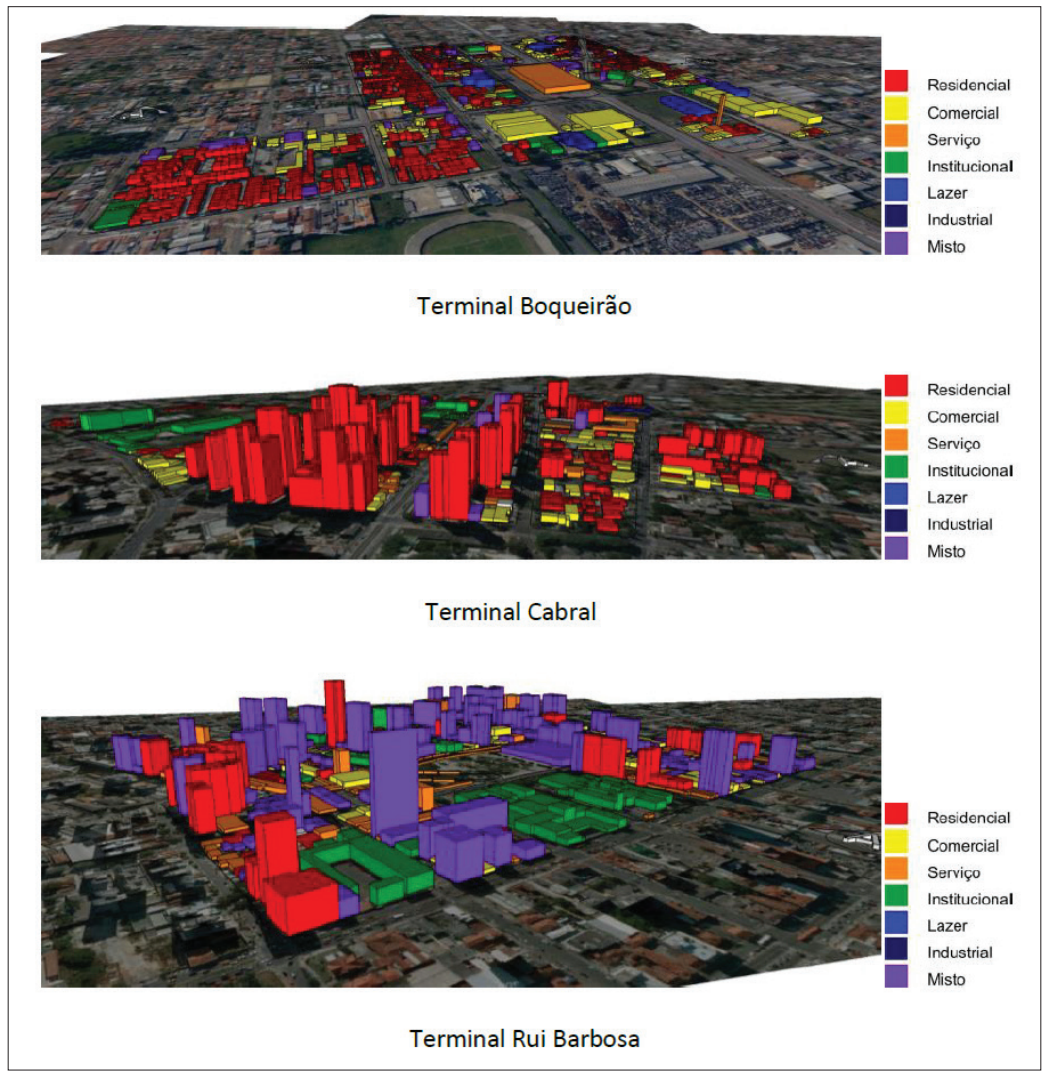

Figura 7 - Perspectiva dos terminais

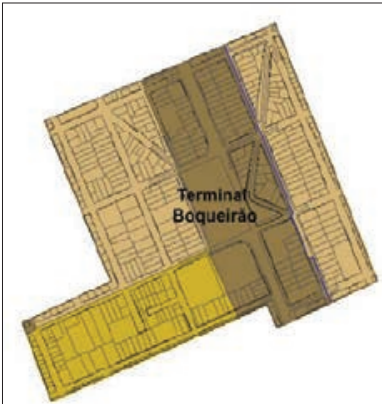

Zoneamento - Lei $n^{\circ} 9.800 / 2000$

Zona Residencial 3 - ZR3

Setor Especial Mal Fioriano - SE-MF

Setor Especial Wenceslau Brás - SE.WB

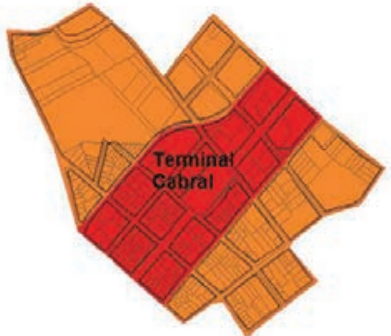

Zoneamento - LeI n' $9.800 / 2000$

Zona Residencial 4 - ZR4

Setor Especial João Gualberto - SE

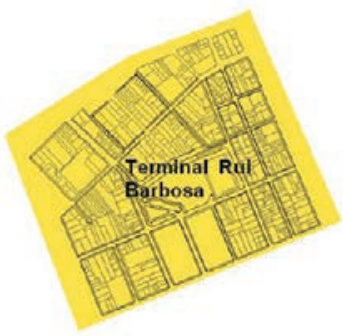

Zoneamento - Lei n' $9.800 / 2000$ Zona Central

Figura 8 - Zoneamentos nos terminais 


\section{DISCUSSÃO DOS RESULTADOS}

As análises foram realizadas a partir dos dados estatísticos e da visualização das figuras geradas pelos dados. Conforme vemos na apresentação dos dados, os terminais configuram formas urbanas diferenciadas, em decorrência dos usos e densidades espaciais existentes, que são subordinados ao zoneamento vigente. Percebemos uma concentração populacional, sendo o terminal Cabral o mais populoso em termos absolutos, mas o terminal Boqueirão com a maior média de habitantes por domicílio. $\mathrm{O}$ terminal Rui Barbosa, apesar dos edifícios altos encontrados, não possui taxa de ocupação populacional significativa pelos usos existentes, que são voltados ao comércio e serviço. O fato de o terminal Boqueirão possuir uma relação de edifícios por quadra maior que o demais terminais, configura uma ocupação com um maior número de edificações de área menor, considerando que as quadras são de tamanhos similares (Tabela 1).

O terminal Praça Rui Barbosa possui características que refletem sua localização central. Com menos uso residencial dando espaço para uso comercial, de serviços e misto (com mais de um uso). O tamanho do lote mínimo, sendo o menor de todos os três terminais, faz com que a configuração espacial reflita o modelo fechado-fechado. Assim como a liberação de altura, pela legislação, aumenta a quantidade de edifícios com mais de 7 (sete) pavimentos (Figura 7).

O terminal Cabral possui mais edifícios com mais de 7 (sete) pavimentos, como um reflexo da legislação vigente que permite uma altura livre ao longo do eixo estrutural (zona $\mathrm{SE}$ ), respeitando um recuo maior à medida que a altura aumenta, o que gera espaços livres entre os edifícios. Situação que no terminal Boqueirão ainda não está sendo explorada no Setor Especial da Avenida Marechal Floriano Peixoto. Já o aproveitamento da zona residencial no terminal Boqueirão é máximo, de acordo com a altura máxima permitida de 3 (três) pavimentos, e considerando que até 2 (dois) pavimentos não há a necessidade de afastamento das divisas, o que permite um maior adensamento das edificações. Por isso, percebemos que a tendência da ocupação urbana, com o crescimento populacional, é as quadras chegarem ao modelo fechado-fechado ocupando toda a quadra com edificações.

Com os resultados obtidos nesta pesquisa, até o momento, foi possível 
a caracterização das diferentes áreas que apesar de estarem no entorno de terminais de ônibus, possuem configurações distintas. O destaque recai sobre a diferenciação do entorno dos terminais Boqueirão e Cabral, uma vez que ambos estão localizados em bairros predominantemente residenciais, com zoneamento com características similares, e mesmo assim possuem morfologias urbanas diferentes. Isso demonstra um processo de ocupação, melhor entendido pelo processo histórico de ocupação e valorização urbana (SOUZA, 2001) e incide na terceira base teórica adotada pelo ISUF, o tempo.

\section{CONCLUSÃo}

A metodologia adotada permitiu desenvolver um projeto de SIG adequado para resolver o problema de entendimento da morfologia urbana das áreas em estudo. A morfologia estuda, a relação da estrutura da forma urbana, tem por objetivo o entendimento não só das diferenças, mas das relações existentes entre essas estruturas (KROPF, 2005).

O estudo da forma urbana permite a verificação de como a aplicação de uma determinada legislação reflete sobre a ocupação do uso do solo, configurando a paisagem local. De modo que essas análises possam servir de subsídio à elaboração de leis futuras visando à manutenção de determinadas estruturas ajustadas às demandas, aos usos e à ocupação urbana.

Esse modelo pode ser aplicado para o restante do município, sendo capaz de identificar homogeneidades e heterogeneidades nas formas urbanas e no perfil populacional. Para o planejamento urbano, o SIG vem resolver problemas geográficos e também subsidiar a tomada de decisão, sendo uma ferramenta para a análise de dados e a visualização de novas perspectivas (LONGLEY et al, 2013). Dentro da rede que compõem o SIG, definido pelas pessoas, software, dados, procedimentos e hardware (LONGLEY et al, 2013), nos dedicamos neste estudo ao desenvolvimento e melhoria dos procedimentos de análise.

Com a elaboração do SIG percebemos que o entendimento da morfologia urbana é possível a partir do entendimento não só de suas formas, mas também dos dados estatísticos que caracterizam a população e a ocupação urbana, sendo um dependente do outro. As formas são visuali- 
zadas pelas imagens de figura-fundo e perspectivas e os dados estatísticos pelos gráficos. Juntos permitiram o entendimento das morfologias urbanas das áreas amostrais.

\section{BIBLIOGRAFIA}

ALTER, C. H. (1976) - Evaluation of Public Transit Services: The Level of Service Concept. Transportation Research Board, n.606, p. 37-40.

COMEC - Coordenação da Região Metropolitana de Curitiba (2005) - Plano de Integração do Transporte da Região Metropolitana de Curitiba.

KROPF, Karl (2005) - The Handling Characteristics or Urban Form. Urban Design, Issue 93.

LAMAS, José M. Ressano Garcia (2004) - Morfologia Urbana e Desenho da Cidade, Fundação Calouste Gulbenkian, 2004.

LEVY, Albert (1999) - Urban Morphology and the problem of the modern fabric: some questions for research. Urban Morphology, 3(2), 79-85.

LONGLEY, Paul A., GOODCHILD Mike F., MAGUIRE David J. \& RHIND, David W. (2013) - Geographic Information System and Science. Bookman.

MOUDON, Anne Vernez (1997) - Urban morphology as an emerging interdisciplinar field. Urban Morphology vol. 1, 3-10.

RODRIGUES, Ferdinando de Moura (1986) - Desenho urbano: cabeça, campo e prancheta. São Paulo : Projeto.

SOUZA, Nelson R. (2001) - Planejamento Urbano em Curitiba: Saber Técnico, Classificação dos Citadinos e Partilha da Cidade. Revista Sociologia Política, Curitiba, 16, p. 107-122.

URBS - Urbanização de Curitiba S.A. (2014) - "Características da RIT". Disponível online no endereço url: http://www.urbs.curitiba.pr.gov.br/transporte/rede-integrada-de-transporte. (acessado em abril de 2014). 
Série Documentos

Imprensa da Universidade de Coimbra

Coimbra University Press

2015

- U M

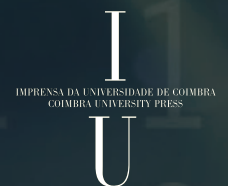

